\title{
RESISTIR PARA PESQUISAR, PESQUISAR PARA RESISTIR: CONSTRUINDO UMA SUSTENTABILIDADE AFETIVA NA UNIVERSIDADE
}

WITHSTAND TO RESEARCH, RESEARCH TO WITHSTAND: BUILDING AN AFFECTIVE SUSTAINABILITY AT THE UNIVERSITY

RESISTENCIA A LA BÚSQUEDA PARA RESISTIR: SOSTENIBILIDAD AFECTIVA EN LA UNIVERSIDAD

\author{
Sonia Regina Vargas Mansano* \\ Mariana Tavares Cavalcanti Liberato**
}

\begin{abstract}
RESUMO
A exigência crescente por pesquisas científicas já se tornou cotidiana nas universidades de nosso país, especialmente naquelas que mantêm um conjunto expressivo de cursos com formação em stricto sensu. O objetivo deste artigo consiste em problematizar essa demanda, explorando dois ângulos do conceito de resistência: a resistência necessária para acolher e lidar com as exigências burocráticas presentes no exercício do pesquisar, e resistência desenhada nas possibilidades de fazer das pesquisas um exercício vivo de pensamento. Esses dois ângulos, que coexistem em nosso tempo histórico, colocam aos pesquisadores o desafio de criar uma prática de pesquisa aliada da transformação social, mas também conectada a experimentação dos afetos e seus desdobramentos. Ao fim do estudo, será possível demonstrar que a prática das pesquisas implica dimensóes burocráticas, mas vai muito além delas, testemunhando também a relevância de formar pesquisadores sensíveis, capazes de acolher e analisar realidades sociais de modo afetivo e contextualizado.
\end{abstract}

Palavras-chave: Resistência. Pensamento. Políticas de pesquisa. Psicologia. Sustentabilidade afetiva. 


\begin{abstract}
The growing requirement for scientific research has already become a daily procedure at the universities of our country, especially those who maintain a significant set of stricto sensu training courses. The goal of this article is to discuss this demand, exploring two angles of the concept of resistance: the resistance needed to receive and deal with the bureaucratic requirements present in the act of researching and resistance designed in the possibilities of turning researches into a living exercise of thought. These two angles, which coexist in our historical time, bring to researchers the challenge of creating a research practice allied to social transformation, but also connected to the experience of affections and their developments. At the end of the study, it will be possible to show that the practice of research implies bureaucratic dimensions, but goes far beyond them, witnessing also the relevance of graduating sensitive researchers, able to receive and analyze social realities in an affective and contextualized way.
\end{abstract}

Keywords: Resistance. Thought. Research policies. Psychology. Affective sustainability.

\title{
RESUMEN
}

El requisito creciente para la investigación científica se ha convertido en algo cotidiano en las universidades de nuestro país, especialmente en aquellas que mantienen un importante conjunto de cursos de formación en el nivel stricto sensu. El objetivo de este artículo es discutir esta demanda, explorando dos ángulos del concepto de resistencia: la resistencia necesaria para recibir y tratar las burocracias en el ejercicio de pesquisar, y las posibilidades de investigar el ejercicio del pensamiento. Estos dos ángulos, que coexisten en nuestro tiempo histórico, pusieron a los investigadores el desafío de crear una práctica de investigación aliada a la transformación social, pero también conectada a la experimentación de los afectos y sus desarrollos. Al final del estudio, será posible mostrar que la práctica de la investigación implica dimensiones burocráticas, pero va mucho más allá de ellas, asistiendo también a la pertinencia de formar investigadores sensibles, capaces de acoger y analizar las realidades sociales de modo afectivo y contextualizado.

Palabras clave: Resistencia. El pensamiento. Políticas de investigación. Psicología. Sostenibilidad afectiva. 


\section{INTRODUÇÃO}

$1 \begin{aligned} & \text { s pesquisas científicas no Brasil têm sido amplamente valorizadas nas } \\ & \text { instituiçóes de ensino superior (IES), especialmente naquelas de âmbito } \\ & \text { público. Docentes ligados a programas de pós-graduação (PPG) são }\end{aligned}$ sistematicamente avaliados e monitorados na realização dessas atividades, sendo eles os profissionais que mais se destacam na produção científica em nosso país. A formação e preparação de pesquisadores nas mais diferentes áreas de conhecimento implica um longo caminho, que é iniciado desde as graduações com os projetos de iniciação científica (IC). Tal formação estende-se aos trabalhos de conclusão de curso (TCC), obrigatórios em algumas graduações e instituições, chegando às dissertações de mestrado e às teses de doutorado.

São diversos e relevantes os estudos (Paludo, 2018; Signorini, 2018) sobre a preparação profissional de pesquisadores e professores, abordando especialmente as implicações políticas de tal atividade. Alguns deles (Cortez, Souza, Amaral, \& Silva, 2017; Levecque, Anseel, Beuckelaer, Heyden, \& Gisle, 2017; Oliveira, Pereira, \& Lima, 2017) enfatizam os processos de saúde e adoecimento dos docentes, por exemplo, no estudo dirigido por Silva Junior (2009), que demonstra o quanto a prática de pesquisa em nosso país passou por um processo de mercantilização amplamente articulado com a internacionalização do saber, o que trouxe uma série de repercussões afetivas para os pesquisadores.

Diante desse cenário complexo de desenvolvimento científico e seus efeitos subjetivos sobre o cotidiano dos pesquisadores, o objetivo deste artigo consiste em abordar a prática da pesquisa no campo problemático de um conceito específico: a resistência. Para tanto, a resistência será analisada em duas perspectivas distintas, mas complementares. Na primeira parte, que foi denominada Resistir para pesquisar, será analisado o quanto é relevante, para sobrevivência dos pesquisadores, criar um corpo suficientemente forte, capaz de entender e atender às exigências burocráticas colocadas para realização de pesquisas em nosso país, sem, com isso, sucumbir em um ressentimento despotencializador. A noção de corpo aqui adotada refere-se aos estudos de Spinosa (2017), que o concebe como capaz tanto de afetar os demais corpos quanto de ser afetado por eles no cotidiano dos encontros. Assim, os encontros transformam o corpo, fazendo variar sua potência de afetar e ser afetado.

Em seguida, na seção denominada Pesquisar para resistir, o conceito de resistência é compreendido como um movimento de criação e um exercício vivo do pensamento nos quais seus participantes (pesquisadores e pesquisados) se 
colocam como agentes transformadores do social conforme se dispóem a apreciar os acontecimentos emergentes, fazendo um exercício conjunto de pensamento, experimentação e aprendizagem.

Ao fim desse trajeto, será possível constatar que os pesquisadores das mais variadas áreas de conhecimento estão diante de um duplo desafio: inscrever-se nos ditames da burocracia que rege as pesquisas nacionais e internacionais, mas também, e talvez mais difícil e desafiador, manter-se aliado da produção crítica, sensível e criadora de problemas que envolvem um exercício vivo do pensamento. Isso requer, em nosso entendimento, a criação de uma sustentabilidade afetiva compreendida aqui como a potência do corpo para acolher, compreender e agir diante dos desdobramentos díspares e inesperados da exigência produtivista que ora recai sobre a academia.

\section{RESISTIR PARA PESQUISAR: A DIMENSÃO BUROCRÁTICA DAS PESQUISAS CIENTÍFICAS}

A Psicologia pode ser considerada uma ciência jovem, tendo seus primeiros estudos científicos datados do fim do século XIX (Figueiredo, 1994). Apesar de sua história recente, a passagem do tempo e os estudos realizados cooperaram para sua ampliação e, principalmente, sua diversificação epistemológica, teórica, metodológica e prática, sendo que seus trabalhos são reconhecidos e utilizados nos mais diferentes campos de intervenção. Concomitante a tal reconhecimento, expandiram-se também os critérios adotados para prover a validação da sua produção científica. Assim, a depender da abordagem utilizada, os elementos e a linguagem requeridos para produção de conhecimento sofrem variações conceituais, metodológicas e de impactos sociais, podendo percorrer um amplo leque que vai das pesquisas qualitativas às quantitativas.

Diante desse cenário multifacetado, a primeira noção de resistência ganha relevância neste estudo. Nessa acepção, a prática da resistência consiste em fortalecer o corpo do profissional da pesquisa, para que este se mantenha ativo diante das crescentes exigências burocráticas e avaliativas ora colocadas. Cabe lembrar que partimos da concepção espinosiana (Spinosa, 2017) de corpo como aquele que é capaz de afetar e ser afetado pelos encontros.

As exigências que recaem sobre os pesquisadores não são poucas: envolvem agências de financiamentos, comitês de ética em pesquisa com animais e seres humanos, tramitação de projetos de pesquisas nas instituições, exigências de publicação, avaliações sistemáticas de agências, índices de citações e pareceristas. Enfim, uma gama de procedimentos tanto preparatórios quanto avaliativos, 
por vezes com dimensões que chegam a ser ritualísticas, mas sem os quais as pesquisas não são colocadas em andamento, não se encerram ou carecem de visibilidade. Tais procedimentos, que deixam clara a dimensão formal e extensiva das pesquisas, são considerados pelas instituições como necessários para conquistar uma posição de reconhecimento público e científico da área, inclusive internacionalmente.

Todavia essa dimensão formal e burocrática que incide sobre as pesquisas científicas, no geral bastante calcadas ainda em uma lógica quantitativa de produção, não abre muito espaço para uma prática de criação que implique linhas mais inventivas e sensíveis no processo de pesquisar. Arendt (2014) expõe essa faceta ao citar uma entrevista do historiador alemão Hans Gumbrecht, na qual ele afirma que os pesquisadores buscam ser cada vez mais científicos, afiliando-se ao padrão das Ciências Naturais. No entanto, ele defende que um intelectual das Ciências Humanas poderia compreender o mundo como algo mais complexo, produzindo alternativas de pesquisa aliadas a uma maneira diferente de construir e compartilhar conhecimentos (Gumbrecht apud Arendt, 2014).

É assim que o primeiro sentido da noção de resistência ganha contornos: aquele que implica abandonar uma posição, digamos, mais ingênua e frágil diante do que está instituído academicamente, adquirindo um conhecimento efetivo sobre as tramitaçôes burocráticas incontornáveis para fazer pesquisa nos dias atuais. $\mathrm{O}$ fortalecimento desse corpo para enfrentar as exigências burocráticas requer pesquisadores capazes de processar informaçōes, utilizar uma linguagem específica e contornar os obstáculos que lhes são frequentemente colocados. Por outro lado, as diversas críticas (Molon, 2004; Rocha \& Rocha, 2004; Romagnoli \& Paulon, 2014) que recaem sobre a tendência psicossocial produtivista são necessárias e preciosas para desnaturalizar esse processo, pois vão produzindo brechas de resistência para serem ocupadas com base em outras formas de conceber e pesquisar.

Diante desse cenário de exigências, faz-se relevante considerar o fortalecimento e a sustentabilidade do corpo afetivo do pesquisador no enfrentamento dessas burocracias. Como compreendemos os afetos? Diferentemente da noção de sentimento, que pressupõe uma dimensão privada, os afetos vêm de fora, mudam a correlação de forças e se presentificam nos encontros, colocando o corpo em contato direto com situações inéditas, inusitadas e imprevisíveis diante das quais é convocado a agir. Assim, a cada nova exigência, é colocado em curso um enfrentamento no qual o corpo é acionado para superar limites ou dificuldades trazidos pelas instituições de pesquisa, pelos governantes (no caso de instituições públicas) ou pelo próprio tema de interesse. Trata-se de um enfrentamento que 
ocorre pela via da invenção: ensaios por meio dos quais alternativas podem ser levantadas e abandonadas, erros e acertos podem ser cometidos (por se tratar de um exercício de produção dupla que envolve a pesquisa e o próprio pesquisador, ambos em movimento). Nesse caso, os agentes envolvidos poderiam fazer das suas experiências espécies de "analisadores" (Baremblitt, 2002, p. 63), diante dos quais os agentes sociais acolhem as situações emergentes e se dedicam à sua análise e transformação, quando for o caso. Os analisadores permitem o acolhimento, a sustentação e a compreensão de cada situação em sua dimensão eventual e política, cuja "materialidade expressiva" é "totalmente heterogênea" (Baremblitt, 2002, p. 63). As análises geradas e compartilhadas nesses encontros podem servir para potencializar as relações interdisciplinares de troca e coprodução de saberes.

Assim, outra face dessa resistência pode ser delineada na necessidade de ocupar as fronteiras entre as abordagens e áreas de conhecimento a fim de fazer com que as Psicologias e as demais áreas se toquem, enfrentem-se e dialoguem na busca de possíveis alianças. Isso tudo só é possível por meio da criação e sustentação de um corpo resistente, poroso e desapegado de verdades, sendo, então, capaz de transitar por espaços de diálogos e trocas por meio dos quais a produção de conhecimento seja expandida e multifacetada.

A dimensão burocrática das pesquisas e a necessidade de um corpo forte que a sustente lembra que o fato de existir não faculta ao vivente escolher fazer "livremente" apenas aquilo de que supostamente gosta, tal como apregoa certo capitalismo difusor de uma existência onipotente e prazerosa. Talvez quem mais coopere para compreender a dimensão inevitável passagem pela burocracia acadêmica seja o próprio Nietzsche, quando diz:

Minha fórmula para a grandeza no homem é amor fati: nada querer diferente, seja para trás, seja para frente, seja em toda eternidade. Não apenas suportar o necessário, menos ainda ocultá-lo - todo idealismo é mendacidade ante o necessário - mas amá-lo [. . .] (Nietzsche, 1995, p. 51).

Amar o necessário e o incontornável não tem nada a ver com a conformação passiva e obediente presente na noção, bastante propagada no campo empresarial, de resiliência. Esta última, em nosso entendimento, propaga uma conotação dócil do corpo do trabalhador, sendo que este deve adaptar-se a um regime econômico autoritário que prega constantemente o sucesso individual à custa do abandono político dos debates, da desconsideração dos afetos e da busca do bem comum. Ao contrário, amar o necessário, tal qual defendemos aqui, requer a construção e sustentação de um corpo afetivamente sensível, mas também organizado, informado, situado e conectado, que visualize as exigências como parte do percurso. Mas, no lugar de simplesmente conformar-se as elas, 
questiona, critica e recusa seus imperativos sempre que necessário, sem se deixar levar pelos ressentimentos que, inevitavelmente, emergirão nesse contato. Cabe, então, transitar da maneira mais leve possível pelo conjunto de exigências, por vezes falacioso, mas sem o qual a produção e compartilhamento das pesquisas podem ficar inviabilizados na engrenagem burocrática ora em vigor.

Tal corpo é ainda mais necessário em um momento histórico no qual a universidade tem sido alvo de críticas sistemáticas, inclusive da parte dos atuais governantes, que insistem em fazer o que denominam de "caça às bruxas" de cientistas e pesquisadores. Tal "caça" recai precisamente sobre aqueles que questionam os procedimentos burocráticos, adotam uma perspectiva crítica para diagnosticar o tempo presente e se dedicam ao estudo de temas que colocam em questão as exclusões sociais, políticas e econômicas que atravessam a sociedade. $\mathrm{Na}$ fala do ministro da Educação, que assumiu o cargo em abril de 2019, essa postura é evidente. Segundo reportagem recente, o ministro disse ser

"Preciso vencer o marxismo cultural nas universidades" e trabalhar para que o país pare "de fazer bobagem" para se chegar a uma situação ideal. E afirmou também que é preciso vencer o comunismo e evitar outras ameaças, como ataques islâmicos, para que o Brasil seja um dos países mais pacíficos do mundo (Oliveira, C., 2019).

Cabe, pois, compreender quais os efeitos políticos da passividade resiliente mencionada acima, que se encontram intimamente relacionados à produção de corpos dóceis e disciplinados (Foucault, 1987). Nesse sentido, as pesquisas vinculadas às áreas das Humanidades e, de maneira geral, à própria existência da universidade pública são colocadas em xeque, haja vista serem grandes aliadas da produção e da sustentação de vidas dissonantes do sistema hegemônico. $\mathrm{O}$ preço por essa posição política é alto, visto que, mais recentemente, elas têm sido cobradas para entrar em um circuito de produção acadêmica voltado aos interesses de uma economia neoliberal. Foi o que também advogou recentemente o ministro da Educação ao dizer que "Em vez de as universidades do Nordeste ficarem aí fazendo sociologia, fazendo filosofia no agreste, [devem] fazer agronomia, em parceria com Israel” (Ministro da Educação, 2019).

Em outra oportunidade, o referido ministro defendeu o contingenciamento de verbas para algumas universidades federais, alegando: "Universidades que, em vez de procurar melhorar o desempenho acadêmico, estiverem fazendo balbúrdia, terão verbas reduzidas. A lição de casa precisa estar feita: publicação científica, avaliações em dia, estar bem no ranking" (Oliveira, E., 2019). Com essa fala (e sem explicitar a qual ranking se referia), o atual governo apresenta os desafios que se desdobram para a proposição desse corpo afetivo, forte, poroso e em aliança. Em vez de meramente defender-se, entretanto, o desafio mostra 
que é preciso construir um coletivo forte para atravessar as linhas instituídas do fazer pesquisa na universidade em tempos de ressentimentos, lançando os pesquisadores na produção de saberes críticos e antidogmáticos.

O que se nota, neste contexto de ataque violento dirigido à educação e à pesquisa, é a proliferação de profissionais que, desqualificados de maneira sistemática em seu trabalho de produção de conhecimento, relatam estar sufocados e em processo de adoecimento (Cortez et al., 2017; Levecque et al., 2017; Oliveira, Pereira, \& Lima, 2017). O problema maior, entretanto, é que esses corpos fiquem expostos ao que Deleuze (2010) chama de esgotamento. Ele afirma: "O esgotado é muito mais do que o cansado" (Deleuze, 2010, p. 65), visto que, imerso nele, o sujeito não consegue ver caminhos, escapes ou perspectivas de desenhar outros rumos para a pesquisa e para universidade. Exaurido de sua força vital para seguir na produção de si, do outro e, no caso aqui analisado, do conhecimento, o esgotado renuncia a sentir, apreciar, preferir ou realizar seja o que for, por mais simples que esse algo possa ser. É o que presenciamos, de maneira frequente, nesta atual política do esgotamento vigente em nosso país e também aplicada à academia: não se trata da mera produção de um corpo cansado pelo excesso de atividades, pelas avaliações acumuladas e pela sistemática desqualificação. Estamos, outrossim, diante de uma intervenção mais perigosa: aquela que pretende esgotar a potência afetiva dos pesquisadores e coloca-los na vizinhança da desistência, desdobrada em apatia e descaso.

Neste atual acirramento de forças, afirmamos que a passividade resiliente está bem distante do corpo potente que resiste. Este último, uma vez capaz de sustentar a multiplicidade de afetos disparados na atualidade e se mantendo suficientemente forte e guerreiro para enfrentar essas adversidades burocráticas e governamentais, abre espaço para outra nuance do verbo resistir: aquela capaz de sustentar e levar adiante um exercício de pensamento na fronteira dos interditos governamentais, dos saberes e da linguagem, voltando-se para a dim.ensão intensiva da pesquisa. Isso leva à segunda dimensão da noção de resistência aqui apresentada.

\section{PESQUISAR PARA RESISTIR: O DIFÍCIL EXERCÍCIO DO PENSAMENTO}

O segundo desafio colocado pelo verbo resistir é, em nosso entendimento, bem mais complexo e difícil de ser conjugado. Trata-se de problematizar quais as possibilidades de praticar a pesquisa em sua dimensão sensível e intensiva. Cabe apreciar, nesta seção, como é possível transitar em um campo problemático e distribuir nele questóes que, de fato, cooperem para colocar em curso um 
exercício do pensamento como criação e não como mera reprodução. Nesse caso, não falamos mais de adotar uma linguagem científica específica ou conhecer a fundo os ditames burocráticos. Evidenciamos, outrossim, as possibilidades de aproximar-se das fronteiras das ciências, dos conceitos e das metodologias, abrindo-se para um campo turbulento de afetos e experimentações que é, em nosso entendimento, condição para produzir um saber vivo e intensivo.

Isso porque, quando a investigação é suficientemente forte, o contato com o problema em pauta agride o pesquisador e o obriga a pensar aquilo que ainda não tem contornos claros. Como diz Deleuze (2003, p. 22): "Em primeiro lugar, é preciso sentir o afeto violento de um signo, e que o pensamento seja como forçado a procurar o sentido do signo". Daí a constatação de que praticar o verbo resistir como um exercício do pensamento que transite pelas imprevisíveis e perturbadoras forças do fora implica inventar e acolher os problemas que se impóem a corpos sensíveis, a pesquisadores sensíveis. Tarefa difícil hoje, visto que componentes de subjetivação mais rudes estão circulando amplamente nesse campo.

Nas pesquisas suficientemente intensas (o que não é uma situação muito comum na academia em razão dos procedimentos, agendas e resultados a serem cumpridos, os quais foram relatados na primeira seção deste artigo), coexistem açōes e paixões que simplesmente minam as pretensões de neutralidade e objetividade do processo. Os afetos díspares, que são vividos no exercício do pensar, evidenciam a falácia das promessas de segurança ancoradas na linguagem, na neutralidade e na razão. Isso porque os afetos, na acepção espinosiana aqui adotada, quando suficientemente fortes, podem lançar os pesquisadores em sustos, incômodos e desassossegos múltiplos. Concebemos a pesquisa, nesse caso, como uma prática política, por meio da qual se busca "liberar a vida lá onde ela é prisioneira, ou de tentar fazê-lo num combate incerto" (Deleuze \& Guattari, 1992, p. 222). O exercício do pensamento como resistência torna-se, assim, o combate afetivo incerto que traz vida e oxigênio à academia e às pesquisas.

Mas, nesse tempo histórico que, como diz Rolnik (2018), sofre de um anestesiamento crônico do corpo afetivo, cabe questionar quais são os corpos capazes de acolher e sustentar um exercício dessa natureza. Como mergulhar em campos problemáticos povoado de sínteses passivas, ou seja, sínteses parciais e provisórias que não culminam em conclusões certeiras, mas que acolhem a incômoda vertigem imposta pelos problemas apreciados e seus desdobramentos imprevisíveis? Diz Deleuze (2000) que os bons problemas insistem e, por isso mesmo, colocam os corpos a inventar uma infinidade de saídas, sempre provisórias, sempre parciais. Ocorre que nem todas as pesquisas são capazes 
de elaborar um problema suficientemente potente para sustentar um campo multifacetado, povoado de afetos, encruzilhadas e questões.

É assim que chegamos à outra face da conjugação do verbo resistir, realizada por meio de um exercício do pensamento: a temporalidade da produção acadêmica é completamente diferente da temporalidade do mercado, tão naturalizada na rapidez e no resultado. $\mathrm{O}$ resistir envolve um devir, tanto dos pesquisadores quanto dos pesquisados, uma vez que as questôes têm a chance de se multiplicar, complicar e implicar, exigindo um tempo nem sempre compatível com a duração definida pelas instituições que regulam as pesquisas (e por seu mais recente agregado, o mercado). Nesse trajeto, são experimentadas agitações afetivas que não foram planejadas; transes e vertigens que não admitem, de maneira imediata, a sucessão de palavras organizadas em um resultado conclusivo. Afinal, não estamos apenas no campo da representação e da razão, mas também no campo das intensidades, no qual as palavras a serem articuladas deixam entrever uma fluidez caótica e testemunham a dificuldade de produzir conhecimento sobre essa matéria indócil que é a vida.

Insistimos que, ao sustentar uma política de pesquisa que esteja mais próxima da artesania e da criação, e não da simples reprodução teórico-burocrática daquilo que já conhecemos, novos afetos podem potencializar o corpo-pesquisante. Nessa perspectiva, seria possível atentar para outra perspectiva de resistir: a de "ser no sentido de estar (o sistere latino) - estar de novo lançado na vida como devir, e nesse sentido também re-existir ou se projetar para fora novamente (re-ek-sistir)" (Oneto, 2006, p. 50). Habitar, novamente, as forças do caos e, com elas, compor outros possíveis para o exercício do pensamento.

Assim, esse segundo sentido do verbo resistir aqui descrito convoca a considerar a função ética e política da pesquisa: trata-se de um resistir que remete à criação de um corpo suficientemente capaz de sustentar o turbilhão de afetos emergentes no campo problemático da pesquisa. Mas se trata também de experimentar e articular saberes por meio dos quais essa intensidade possa ser compartilhada e colocada em circulação, a fim de provocar rachaduras nas certezas da ciência e das profissões. Rachaduras estas que são vitais para toda e qualquer área de conhecimento.

Deste modo, a própria escrita da pesquisa e os produtos dela derivados ganham, também, um novo valor: não mais quantitativo que culmine apenas na publicação, mas qualitativo e pautado por um paradigma ético-estético, que não aparta as formas de construir conhecimento dos modos de criação da própria existência. Além disso, aponta para a dimensão de uma política de produção no, do, para e com o coletivo. Essa coprodução engendra possibilidades de encontros 
de compartilhamento e socialização dos saberes entre os pesquisadores que, distantes das rivalidades e da competitividade prisioneiras da lógica capitalista de produção, promovem o contato com as diferenças, os enfrentamentos e as alianças. Todos esses contatos afetivos são vitais para produção científica e impulsionam o exercício do pensar.

Ainda nesse plano da resistência, como exercício vivo do pensamento, cabe mencionar, por último, a necessidade urgente de defender a universidade dos ataques que ela vem sofrendo, especialmente nos últimos meses. Mas qual universidade cabe defender? Acreditamos que seja aquela capaz de proliferar práticas de resistência pela via do pensamento, colocando em circulação linhas de subjetivação múltiplas e potentes para acionar a cocriação, a sensibilidade, a crítica e a invenção de outros mundos possíveis.

Nesse caso, falamos na defesa de uma universidade que, distante do ensino a distância, atribua à presença nas salas de aula, nos campos de estágios e nas supervisões seu maior valor e, assim, invista na experiência afetiva de alianças que desemboquem na transformação de si, do outro e da sociedade. Uma universidade capaz de sustentar os afetos múltiplos e díspares que habitam a produção científica e os problemas que são colocados em pauta pelos pesquisadores, pelos estudantes e pela sociedade. Pode-se dizer que, expostos aos ataques ora em curso, encontramo-nos em um tempo histórico que, ao mesmo tempo, assombra e convoca o pensamento. A questão é analisar como e com quais afetos entramos nesse turbilhão, já que não nos é facultado estar fora dele. Em que medida habitamos um corpo esgotado e vencido pelas investidas do capitalismo neoliberal? Ou ainda, em que medida dispomos de um corpo sensível, capaz de sustentar a adversidade das experiências e transmudá-las em favor da vida?

Nesse momento, já acumulamos condições conceituais para mostrar a urgência de tecer uma sustentabilidade afetiva na academia. Esta implica experimentar e sustentar os afetos díspares advindos da produção científica e colocar em curso, no coletivo, a crítica necessária para oxigenar o conhecimento, enfrentar as burocracias esgotantes, questionar o atual estado de coisas e dar passagem ao diverso. É precisamente isso que vem sendo atacado nas universidades neste momento histórico: sua prática efetiva de resistência que valoriza o difícil exercício do pensar e viver juntos no lugar da mera aplicação instrumental, produtivista, individualista e avaliativa.

Essa luta fica ainda mais acirrada diante da organização socioeconômica ora vigente, que necessita individualizar para prosperar em lucro. Cabe, então, subverter essa noção de lucro, colocando em seu lugar outros valores, como a 
potência das fronteiras, das alianças e dos encontros, mostrando a concretude de outras possibilidades de vida e coinventando novos coletivos de luta pela expansão e democratização do conhecimento. Fica cada vez mais clara a luta para que a academia seja um espaço de múltiplos fluxos, de díspares conexões e de experimentações na produção de saberes.

\section{CONSIDERAÇÕES FINAIS: INQUIETAÇŌES PRODUZIDAS POR UMA POLÍTICA DE PESQUISA QUE SUSTENTE A RESISTENNCIA E OS AFETOS}

No decorrer deste estudo, ficou claro que o trabalho exaustivo de produção de conhecimento, protagonizado pelos pesquisadores, envolve dimensões burocráticas que tendem a sequestrar tempo e energia para sua realização. Diante de tais exigências, não é possível manter-se ingênuo, fazendo uma crítica rasa ou simplesmente se negando a seguir seus protocolos. Isso decretaria a impossibilidade de fazer pesquisa em um tempo histórico ainda marcado pela ideia positivista de ciência e inserido em uma trama de forças políticas, sociais e econômicas notadamente atravessadas pela produtividade.

Por outro lado, se o sequestro aí exercitado é amplamente despotencializador, ele não é capaz de simplesmente condenar os profissionais ao mero exercício burocrático. Assim, outra dimensão do pesquisar abre-se quando consideramos as práticas de resistência atualizadas na formação de pesquisadores sensíveis, capazes de acolher e analisar realidades sociais em sua complexidade de forças vidas. Para tanto, valem-se de um corpo afetivo, intensivo e aberto para mergulhar nas singularidades do problema investigado, produzindo brechas e fissuras.

Escolher apenas um dos sentidos do verbo pesquisar (burocrático ou criador) é, em nosso entendimento, diminuir a potência da academia. Ao passo que acolher a diversidade que eles colocam em curso remete-nos à relevância de colocar em ação, cotidianamente, uma sustentabilidade afetiva nas práticas de pesquisa realizadas nas universidades. É com esse conceito que concluímos nossa argumentação. Por sustentabilidade afetiva entendemos a potência dos corpos para acolher, experimentar, elaborar e transformar os afetos díspares que emergem nos encontros com os outros. Tais outros podem ser os problemas de pesquisa e suas mutações, os participantes e seus relatos de vida, os procedimentos burocráticos, as situações inesperadas, as descobertas e saídas coinventadas por pesquisadores e participantes. Enfim, um amplo leque de situações que coloca o corpo em contato afetivo com as forças do fora que invadem cotidianamente as pesquisas.

Estaríamos à altura de acolher, sustentar e conjugar o verbo resistir nessas 
duas acepçôes? Se não, já está na hora de abordar esse limite no cotidiano dos cursos de pós-graduação em nosso país. Sem isso, corremos o risco de mergulhar no silêncio do esgotado. E não seria precisamente esse silêncio um disparador de adoecimento da e na academia?

Nesse sentido, arriscamo-nos a afirmar que o exercício da resistência na universidade pode constituir um território singular de produção para sustentar afetivamente uma "frágil saúde irresistível" (Deleuze, 1997, p. 14) que não se dobre ao esgotamento. Esta se abre à invenção de possibilidades de vida que não se limitam a formas individualizadas e automatizadas de responder às demandas institucionais, mas produzem variações nos encontros entre ideias, olhares, sensações e movimentos. 


\section{REFERÊNCIAS}

Arendt, R. (2014). Aos prezados colegas da comissão de avaliação dos Programas de Pós-Graduação em Psicologia da CAPES. In A. G. Bernardes, G. M. Tavares, \& M. Moraes. Cartas para pensar: politicas de pesquisa em Psicologia. Vitória: EdUFES.

Baremblitt, G. (2002). Compêndio de análise institucional e outras correntes: teoria e prática. Belo Horizonte: Instituto Félix Guattari.

Cortez, P. A., Souza, M. V. R., Amaral, L. O., \& Silva, L. C. A. (2017). A saúde docente no trabalho: apontamentos a partir da literatura recente. Cadernos Saude Coletiva, 25(1), 113-122. Recuperado a partir de https://doi. org/10.1590/1414-462x201700010001

Deleuze, G. (1997). Crítica e clínica. São Paulo: Ed. 34.

Deleuze, G. (2000). Lógica do Sentido. São Paulo: Perspectiva.

Deleuze, G. (2003). Proust e os signos. Rio de Janeiro: Forense Universitária.

Deleuze, G. (2010). Sobre o teatro: um manifesto de menos: o esgotado. Rio de Janeiro: Jorge Zahar.

Deleuze, G., \& Guattari, F. (1992). O que é a filosofia? Rio de Janeiro: Ed. 34.

Figueiredo, L. C. (1994). A invenção do psicológico: quatro séculos de subjetivação 1500-1900. São Paulo: Escuta.

Foucault, M. (1987). Vigiar e punir: nascimento da prisão. Petrópolis: Vozes.

Levecque, K., Anseel, F., Beuckelaer, A., Heyden, J. V., \& Gisle, L. (2017, May). Work organization and mental health problems in $\mathrm{PhD}$ students. Research Policy, 46(4), 868-879. Recuperado a partir de https://doi.org/10.1016/j. respol.2017.02.008

Ministro da Educação acha que as universidades do Nordeste não deveriam ensinar sociologia. (2019, 8 abril). Revista Fórum. Recuperado a partir de https://revistaforum.com.br/politica/ministro-da-educacao-acha-queuniversidades-do-nordeste-nao-deveriam-ensinar-sociologia/

Molon, S. I. (2004). Algumas questôes epistemológicas e éticas da Psicologia: a avaliação em discussão. Psicologia e Sociedade, 16(1), 108-123. 
Nietzsche, F. (1995). Ecce homo: como alguém se torna o que é. São Paulo: Companhia das Letras.

Oliveira, A. S. D., Pereira, M. S., \& Lima, L. (2017, setembro-dezembro). Trabalho, produtivismo e adoecimento dos docentes nas universidades públicas brasileiras. Psicologia Escolar e Educacional, 21(3), 609-619.

Oliveira, C. (2019, 8 abril). Bolsonaro coloca executivo do mercado financeiro como ministro da Educação. Rede Brasil Atual. Recuperado a partir de https:// www.redebrasilatual.com.br/educacao/2019/04/bolsonaro-coloca-executivodo-mercado-financeiro-como-ministro-da-educacao

Oliveira, E. (2019, 7 maio). Não há corte, há contingenciamento, diz ministro sobre orçamento das universidades federais. Portal G1-Globo.com. Recuperado a partir de https:/g1.globo.com/educacao/noticia/2019/05/07/nao-ha-corteha-contingenciamento-diz-ministro-da-educacao-sobre-orcamento-dasuniversidades-federais.ghtml

Oneto, P. D. (2006). Vontade de arte e resistência ao presente. In V. R. F. Colaço, F. P. H. A. Pinheiro, \& J. F. Silva (Orgs.), Reflexos III - PET-Psicologia/UFC: políticas de subjetivação nas práticas sociais. [CD-ROM]. (pp. 45-55). Fortaleza: Edições UFC, Programa de Educação Tutorial.

Paludo, C. (2018). Contexto nacional e as exigências para a pesquisa em educação. Revista Brasileira de Educação, 23, e230062. Recuperado a partir de http://dx.doi.org/10.1590/s1413-24782018230062

Rocha, M. L., \& Rocha, D. (2004). Produção de conhecimento, práticas mercantilistas e novos modos de subjetivação. Psicologia \& Sociedade; $16(1$ núm. especial), 3-36.

Rolnik, S. (2018). Esferas da insurreição: notas para uma vida não cafetinada. São Paulo: N-1.

Romagnoli, R. C., \& Paulon, S. M. (2014). Escritas implicadas, pesquisadores implicantes: notas sobre os destinos da subjetividade nos desatinos da produção científica. In M. Dimenstein, \& J. F. Leite (Orgs.), Psicologia em pesquisa: cenários de práticas e criaçôes. (pp. 23-42). Natal: EdUFRN.

Signorini, I. (2018). Legitimação de políticas científicas locais em função de demandas de internacionalização da universidade. Cadernos CEDES, 38(105). Recuperado a partir de https:/www.scielo.br/pdf/ccedes/v38n105/16787110-ccedes-38-105-205.pdf 
Silva Júnior, J. R. (2009). O professor pesquisador nas universidades públicas no contexto da internacionalização do capital: a produtividade do trabalho imaterial superqualificado. Revista Portuguesa de Educação, 22(1), 145-177.

Spinoza, B. (2017). Ética. Belo Horizonte: Autêntica. (Publicado originalmente em 1677). 